\title{
Achieving development goals for HIV, tuberculosis and malaria in sub-Saharan Africa through integrated antenatal care: barriers and challenges
}

Freya J. I. Fowkes ${ }^{1,2,3,4^{*}}$, Bridget L. Draper ${ }^{1}$, Margaret Hellard ${ }^{1,2}$ and Mark Stoové $e^{1,2}$

\begin{abstract}
Background: The global health community is currently transitioning from the Millennium Development Goals (MDGs) to the Sustainable Development Goals (SDGs). Unfortunately, progress towards maternal, newborn and infant health MDGs has lagged significantly behind other key health goals, demanding a renewed global effort in this key health area. The World Health Organization and other institutions heralded integrated antenatal care (ANC) as the best way to address the inter-related health issues of HIV, tuberculosis (TB) and malaria in the high risk groups of pregnant women and infants; integrated ANC services also offer a mechanism to address slow progress towards improved maternal health.

Discussion: There is remarkably limited evidence on best practice approaches of program implementation, acceptability and effectiveness for integrated ANC models targeting multiple diseases. Here, we discuss current integrated ANC global guidelines and the limited literature describing integrated ANC implementation and evidence for their role in addressing HIV, malaria and TB during pregnancy in sub-Saharan Africa. We highlight the paucity of data on the effectiveness of integrated ANC models and identify significant structural barriers in the health system (funding, infrastructure, distribution, human resources), the adoption system (limited buy-in from implementers, leadership, governance) and, in the broader context, patient-centred barriers (fear, stigma, personal burdens) and barriers in funding structures. We highlight recommendations for action and discuss avenues for the global health community to develop systems to integrate multiple disease programs into ANC models of care that better address these three priority infectious diseases.
\end{abstract}

Summary: With the current transition to the SDGs and concerns regarding the failure to meet maternal health MDGs, the global health community, researchers, implementers and funding bodies must work together to ensure the establishment of quality operational and implementation research to inform integrated ANC models. It is imperative that the global health community engages in a timely discussion about such implementation innovations and instigates appropriate actions to ensure advances in maternal health are sufficient to meet applicable SDGs.

Keywords: Antenatal care, HIV, Tuberculosis, Malaria, Integrated services

\footnotetext{
* Correspondence: freya.fowkes@burnet.edu.au

'Macfarlane Burnet Institute of Medical Research, Melbourne, Australia

${ }^{2}$ Department of Epidemiology and Preventive Medicine, Monash University,

Melbourne, Australia

Full list of author information is available at the end of the article
}

\section{Biomed Central}

(c) The Author(s). 2016 Open Access This article is distributed under the terms of the Creative Commons Attribution 4.0 International License (http://creativecommons.org/licenses/by/4.0/), which permits unrestricted use, distribution, and reproduction in any medium, provided you give appropriate credit to the original author(s) and the source, provide a link to the Creative Commons license, and indicate if changes were made. The Creative Commons Public Domain Dedication waiver (http://creativecommons.org/publicdomain/zero/1.0/) applies to the data made available in this article, unless otherwise stated. 


\section{Background}

The 2000 Millennium Development Goals (MDGs) established a global development framework aimed at improving health and saving the lives of the world's poorest [1]. Three of the eight MDG targets related directly to health: reducing child mortality (goal 4); improving maternal health (goal 5); and combating HIV, malaria and other diseases (goal 6) (Table 1). The health outcomes described in these goals have overlapping risk exposures that lend themselves to common and integrated responses. Health remains a key focus of the Sustainable Development Goals (SDGs), which again encourage an integrated response to major global health issues [2].

In the SDGs, combating HIV, tuberculosis (TB) and malaria now resides within a broader health goal - Ensure healthy lives and promote well-being for all at all ages (goal 3) - with a specific call to end the epidemics of HIV, TB and malaria by 2030 [2] (Table 1). Given the prominence of maternal, newborn and child health across multiple goals, classifying goals targeting the same beneficiaries as distinct and interdependent clusters has been suggested to enhance the achievement of the SDGs [3]. The World Health Organization (WHO) and other institutions have endorsed integrated antenatal care (ANC) as the best strategy to address the interrelated health issues of HIV, TB and malaria, as well as other vaccine-preventable infectious diseases and nutritional deficiencies, in the high risk groups of pregnant women and infants [4-8]. By providing a comprehensive disease prevention approach, integrated ANC services can help accelerate progress towards maternal, newborn and child health goals (MDG achievements and current burden of disease are outlined in Table 1) by offering an efficient mechanism to counter the impact of fragmented service delivery. An integrated ANC approach to these diseases seems highly plausible and intuitively beneficial. The global reach of ANC programs is extensive, with ANC coverage being approximately $70 \%$ in sub-Saharan Africa, the region that harbours the highest burden of HIV, malaria and TB globally and where ANC often represents a woman's first contact with the healthcare system $[4,9]$. Statistics

Table 1 Millennium and Sustainable Development Goals addressing HIV, TB and malaria or maternal, newborn and child health and sub-Saharan African achievements and statistics

\begin{tabular}{|c|c|}
\hline Millennium Development Goals [1] & 2015 sub-Saharan Africa achievement [1] \\
\hline \multicolumn{2}{|l|}{ Goal 4: Reduce Child Mortality } \\
\hline $\begin{array}{l}\text { Target 5: Reduce by two-thirds, between } 1990 \text { and 2015, the under-five } \\
\text { mortality rate }\end{array}$ & $52 \%$ reduction in child mortality \\
\hline \multicolumn{2}{|l|}{ Goal 5: Improve Maternal Health } \\
\hline $\begin{array}{l}\text { Target 6: Reduce by three-quarters, between } 1990 \text { and 2015, the maternal } \\
\text { mortality ratio }\end{array}$ & $49 \%$ reduction in maternal mortality ratio \\
\hline \multicolumn{2}{|l|}{ Goal 6: Combat HIV/AIDS, Malaria and Other Diseases } \\
\hline Target 7: Have halted by 2015 and begun to reverse the spread of HIV/AIDS & $51 \%$ reduction in new HIV infections \\
\hline $\begin{array}{l}\text { Target 8: Have halted by } 2015 \text { and begun to reverse the incidence of } \\
\text { malaria and other major diseases }\end{array}$ & $\begin{array}{l}69 \% \text { reduction in malaria mortality in the under-five } \\
\text { age group }\end{array}$ \\
\hline Sustainable Development Goals [2] & 2015 sub-Saharan burden of disease \\
\hline \multicolumn{2}{|l|}{ Goal 3: Good Health and Well-being } \\
\hline $\begin{array}{l}\text { 3.1: By } 2030 \text {, reduce the global maternal mortality ratio to less than } 70 \text { per } \\
100,000 \text { live births }\end{array}$ & 546 per 100,000 live births [75] \\
\hline $\begin{array}{l}\text { 3.2: By } 2030 \text {, end preventable deaths of newborns and under-five children, } \\
\text { with all countries aiming to reduce neonatal mortality to at least as low } \\
\text { as } 12 \text { per } 1000 \text { live births and under-five mortality to at least as low as } \\
25 \text { per } 1000 \text { live births }\end{array}$ & $\begin{array}{l}\text { Neonatal and under-five mortality is } 29 \text { and } 83 \text { per } \\
1000 \text { live births, respectively [75] }\end{array}$ \\
\hline $\begin{array}{l}\text { 3.3: By 2030, end the epidemics of AIDS, TB, malaria and neglected tropical } \\
\text { diseases and combat hepatitis, water-borne diseases and other } \\
\text { communicable diseases }\end{array}$ & $\begin{array}{l}2.6(0-20.1) \text { new HIV infections per } 1000 \text { uninfected } \\
\text { population }{ }^{a}[76] \\
281(22-852) \text { new TB cases per 100,000 population }{ }^{a}[76] \\
268.6(3.6-460.9) \text { new malaria cases per } 1000 \text { population } \\
\text { at risk }{ }^{\mathrm{a}}[76]\end{array}$ \\
\hline $\begin{array}{l}\text { 3.8: Achieve universal health coverage, including financial risk protection, } \\
\text { access to quality essential healthcare services and access to safe, } \\
\text { effective, quality and affordable essential medicines and vaccines } \\
\text { for all }\end{array}$ & $\begin{array}{l}\text { HIV treatment coverage } 0-70 \%^{\mathrm{b}}[77] \\
\text { TB treatment coverage } 10-70 \%^{\mathrm{b}}[77] \\
\text { IPTp coverage } 17-40 \%[37] \\
\text { Use of ITNs } 10-70 \%{ }^{\mathrm{b}}[77]\end{array}$ \\
\hline
\end{tabular}

ITN insecticide-treated net, TB tuberculosis, IPTp intermittent preventive therapy in pregnancy

a2014 statistics for WHO Africa region

${ }^{b} 2015$ statistics for WHO Africa region 
on the potential impact of integrating these services into ANC remain limited, with no available published data on the impact of HIV services integrated into ANC on maternal morbidity or mortality, despite $25 \%$ of maternal deaths in sub-Saharan Africa being attributable to HIV [10]. Additionally, there is no data estimating the potential role of integrated ANC services on preventing mother-to-child HIV transmission, except for a recent systematic review (three of the four studies were based in sub-Saharan Africa) where a higher than two-fold increase was observed in pregnant women commencing antiretroviral therapy (ART) in ANC clinics integrating ART within their service compared to women attending clinics without ART integration [11]. A review of integrating intermittent preventive therapy in pregnancy (IPTp) and bed nets into ANC also estimated a reduction in all-cause child mortality of 32 and 18\%, respectively [12]. Others have reported that incorporating TB screening and diagnosis into ANC may detect and treat an additional 167,200 TB cases globally [13], which would help reduce the $40 \%$ maternal mortality rate of untreated TB in pregnancy $[14,15]$. In this context, integrated ANC offers enormous potential to reduce the global burden of disease through the provision of same day, same site testing and treatment for HIV/ AIDS, malaria and TB as part of routine care for pregnant women.

Despite this potential, the rise in funding for singledisease programs, commonly focused on HIV/AIDS and malaria, undermines efforts to overcome fragmentation in health systems [16, 17]. Such a focus on singlediseases has extended to ANC; rather than focusing on integrated services that address multi-disease health priorities in maternal, newborn and child health, the literature largely describes integrated services that combine ANC with a single-disease focus (reviewed in [18]). We argue that, despite $\mathrm{WHO}$ recommendations, there is a remarkable lack of evidence on best practice approaches of program implementation for integrated ANC models in sub-Saharan Africa and beyond.

The issues for implementation of integrated ANC are broad and multifaceted. Here, we focus on implementation challenges of integrating HIV, malaria and $\mathrm{TB}$ services into ANC models in sub-Saharan Africa and identify a paucity of evidence demonstrating their effectiveness in addressing these multiple disease outcomes in these high risk populations. Our discussion of implementation challenges is guided by a conceptual framework that considers the problem - the prioritisation of SDGs in maternal, newborn and child morbidity and mortality and the complexity of overcoming implementation barriers - alongside the potentially effective intervention of HIV, TB and malaria services integration into ANC within the health system. We consider ways to improve the implementation of the integrated
ANC intervention within a framework that first addresses health system strengthening to deliver quality service models through the development and maintenance of adequate physical and technical infrastructure. Second, we consider the adoption of the system and the need for buy-in from local governments and ANC staff to support integrated ANC models. Finally, we use the framework to consider the broader contextual factors such as the community and psycho-social impact of delivering prevention and care interventions, negative social attitudes to specific diseases, siloed and diseasespecific funding models, and implementation and funding issues associated with the specific responsibilities assumed by different levels of government. We discuss avenues for the global health community to develop and maintain integrated ANC models of care, and consider how our findings are broadly relevant to other interventions aimed at mothers, their newborns and children. In 2016, with the transition from the MDGs to the SDGs and progress towards maternal, infant and child health goals lagging in sub-Saharan Africa (Table 1), it is imperative that the global health community discusses and instigates appropriate action to ensure sufficient advances in maternal, newborn and child health are made to accelerate the progress towards the relevant SDGs.

\section{Global guidelines for HIV, TB, malaria and ANC}

The integration of HIV, TB and malaria interventions into ANC was given only limited attention in the WHO's 2002 multicentre trial of a new evidence-based ANC model $[19,20]$. Developed specifically for the management of low-risk pregnant women in resource-poor settings, the streamlined model of care that limited the number of tests and clinical procedures to those necessary for identifying special health conditions and women at risk of developing complications, performed similarly in randomised controlled trials with respect to maternal, newborn and child health outcomes (e.g. pre-eclampsia, urinary tract infections, low birth weight) to the standard "Western" ANC model [19, 20]. Beyond general recommendations for HIV rapid point-of-care testing and treatment initiation through specialised care referral for the prevention of mother-to-child transmission of HIV (PMTCT) and IPTp for malaria (prophylaxis in pregnancy in the absence of screening), the guidelines provided limited practical information on service implementation and disease screening and care.

The potential for integrated health services to address the three health-related MDGs received renewed attention in 2008 in the WHO's technical brief, Integrated Health Services - What and Why? [16], where a renewed fight against health service fragmentation through integrated service delivery was called for. The technical brief outlined that, for the user, integrated 
healthcare should be "seamless, smooth and easy to navigate" ([16]; p. 5). Fully integrated ANC would see pregnant women in sub-Saharan Africa attending ANC clinics to receive health education, HIV counselling, testing and appropriate treatment, long-lasting insecticidetreated nets, IPTp, and TB screening and treatment (WHO guidelines summarised in Table 2) as well as other health services (e.g. screening and treatment of syphilis, anaemia and nutritional interventions) as required. In theory, such a model of integrated ANC should markedly improve the coverage, uptake and retention in care, and reduce the time to treatment initiation for these disease-specific health interventions. However, recent reports show that implementation of such service models in sub-Saharan Africa are minimal and the available data on HIV, malaria and TB services in ANC demonstrates that intervention coverage is low (Table 2).
To date, published research into the effectiveness of integrated ANC in sub-Saharan Africa has almost exclusively focused on HIV and malaria. Controlled trials and observational studies generally demonstrated relative increases in pregnant women and infants being tested for HIV (range 40-200\%), initiating treatment for the PMTCT (35-400\% relative increase) and reductions in loss-to-follow-up (50\% relative reduction) within integrated versus non-ANC-integrated approaches across a number of sub-Saharan African countries [11, 18, 21-33]. Integration of HIV into ANC is likely to have contributed significantly to achieving an ART coverage to prevent PMTCT of $73 \%$ among pregnant women living with HIV globally [34]. While this increase in coverage will play a role in helping achieve global 90-90-90 HIV prevention targets (90\% diagnosed, $90 \%$ on treatment and $90 \%$ virally suppressed [35]) and are key to PMTCT, men remain the

Table 2 WHO guidelines, national guidelines and implementation coverage on HIV, malaria, TB, prevention, screening and treatment during pregnancy in sub-Saharan Africa

\begin{tabular}{|c|c|c|c|}
\hline Intervention & WHO recommendations ${ }^{a}$ & Inclusion in national guidelines ${ }^{\mathrm{b}}$ & Coverage $(\%)^{\complement}$; median (range) \\
\hline \multicolumn{4}{|l|}{ HIV } \\
\hline Prevention & ART prophylaxis from 14 weeks for PMTCT & Yes & No data \\
\hline Screening & HIV testing at first ANC visit & Yes & $\begin{array}{l}37.9 \% \\
(14.7-52.4 \%)\end{array}$ \\
\hline Treatment & $\begin{array}{l}\text { ART for mother starting immediately if CD4 count } \\
\leq 350 \text { cells } / \mathrm{mm}^{3} \text { for mother's own health } \\
\text { (treatment of HIV and PMTCT) }\end{array}$ & Sometimes & No data \\
\hline \multicolumn{4}{|l|}{ Malaria } \\
\hline \multirow[t]{2}{*}{ Prevention } & $\begin{array}{l}\text { IPTp at each ANC visit from } 2^{\text {nd }} \text { trimester to delivery, } \\
\text { doses } \geq 1 \text { month apart, preferably DOT }\end{array}$ & Sometimes & $\begin{array}{l}6.6 \% \\
(0.1-40.9 \%)^{d}\end{array}$ \\
\hline & Receive one LLIN through ANC visits & Sometimes ${ }^{\mathrm{e}}$ & $\begin{array}{l}39.7 \% \\
(16.0-75.4 \%)^{f}\end{array}$ \\
\hline Screening & No guidelines & N/A & N/A \\
\hline Treatment & $\begin{array}{l}\text { 'Effective case management' - presumptive treatment } \\
\text { of symptoms/fever as per national guidelines }\end{array}$ & Rarely & No data \\
\hline \multicolumn{4}{|l|}{ TB } \\
\hline Prevention & TB infection control in PMTCT settings & No & No data \\
\hline Screening & $\begin{array}{l}\text { TB signs and/or symptoms should be evaluated for } \\
\text { active TB } \\
\text { HIV positive pregnant women should be screened for } \\
\text { TB during HIV post-test counselling }\end{array}$ & $\begin{array}{l}\text { Rarely } \\
\text { Rarely }\end{array}$ & $\begin{array}{l}\text { No data } \\
\text { No data }\end{array}$ \\
\hline Treatment & All first-line TB drugs (except streptomycin) & No & No data \\
\hline
\end{tabular}

ANC antenatal care, ART antiretroviral therapy, DOT directly observed treatment, IPTp intermittent preventive therapy in pregnancy, ITN insecticide-treated net, LLIN long-lasting insecticide-treated net, SP sulfadoxine-pyrimethamine, TB tuberculosis, PMTCT prevention of mother-to-child transmission

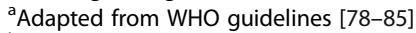

${ }^{b}$ National Guidelines of the nine countries (Botswana, Tanzania, Uganda, Liberia, Mozambique, Namibia, Nigeria, South Africa, and Swaziland) with accessible guidelines/policies/strategies on Ministry of Health (or similar) websites. The recommended components of ANC vary widely between and within countries, often depending on the level of care (community, district, regional or national) at which ANC is provided. Other components generally included in ANC are blood tests for blood group, anaemia, HIV and syphilis, urine dipstick for protein and glucose, checking blood pressure, providing tetanus toxoid, iron and folic acid, assessment of substance use, and performing nutrition and hygiene counselling

IImplementation coverage data is based on STATcompiler: The DHS Program. Data is median (range) coverage data available for HIV screening (data from four countries) and malaria prevention (IPTp 34 countries; ITN/LLIN 25 countries)

${ }^{\mathrm{d} C o v e r a g e}$ is reported as percentage of women receiving $3+$ doses of SP/Fansidar, with at least one dose during ANC visit (DOT)

eIncluding any reference to provision of LLINs, ITNs or mosquito nets in general

fPercentage coverage of pregnant women who slept under a LLIN the night before the survey 
primary target for the HIV prevention impact achieved from increasing ART coverage in sub-Saharan Africa, given they are the dominant source of transmission [36]. Incorporation of IPTp for malaria into ANC in subSaharan Africa has been recommended for over a decade, but calls for IPTp integration have achieved more moderate success, with only 40 and $17 \%$ of women living in malaria endemic areas receiving more than two or three doses of IPTp, respectively, in 2015 [37]. Compared with HIV and malaria, there is a paucity of data on the effectiveness of integrating TB care into ANC clinics. A pilot study in Kenya, examining the integration of $\mathrm{TB}$ screening and treatment into ANC, reported a $91 \%$ increase in the number of women screened for TB; however, no outcomes on treatment adherence or clearance of infection were reported [38].

Given the call for multiple-disease, fully integrated ANC models [16], it is disappointing that nearly all the published literature focuses on the integration of singledisease services into ANC. This represents a crucial gap and impedes the adoption of evidence-based approaches in the development of effective integrated ANC services that target multiple diseases. The identification of the barriers and enablers for the successful integration of services that simultaneously address multiple diseases is needed to optimise new ANC models and vitally important to support progress towards meeting global development goals related to maternal, newborn and child health.

\section{Challenges in implementing integrated ANC: structural barriers in health infrastructure and adoption systems}

Many challenges exist in cross-disease integrated ANC in sub-Saharan Africa. Structural barriers often manifest in the characteristics of the health system (Table 3). Weak program links, health systems, and financial infrastructure are cited as a prominent barriers to ANC attendance and integrated ANC service delivery (systematically reviewed in $[18,39,40])$. For example, the provision of HIV treatment at specialised ART clinics separate to ANC clinics reduced uptake of HIV services in pregnant women by around $50 \%[21,29,30]$. To counter this problem, governments, in conjunction with non-governmental organisations, have begun integrating HIV services and PMTCT into primary healthcare and ANC with the recognition that HIV-specific resources could be allocated diagonally (aiming for disease-specific results through enhanced health systems) [18, 41]. However, integration of these services can be hindered if not accompanied by sufficient additional funding to ensure cohesive and effective service integration; limited resources remain a major barrier in the integration of malaria treatment and prevention into ANC [42]. To achieve effective integration of HIV, TB and malaria
Table 3 Key health system, adoption system and broader context barriers to integration of HIV, TB and malaria services into antenatal care

\begin{tabular}{|c|c|}
\hline \multicolumn{2}{|l|}{ Health system characteristics } \\
\hline \multirow[t]{3}{*}{$\begin{array}{l}\text { Insufficient resources and } \\
\text { financial infrastructure }\end{array}$} & $\begin{array}{l}\text { - Weak disease-specific and antenatal } \\
\text { care program links }\end{array}$ \\
\hline & - Weak health systems \\
\hline & $\begin{array}{l}\text { - Financing of health services may be } \\
\text { required to change to fit integration } \\
\text { of previously separate services }\end{array}$ \\
\hline \multirow[t]{2}{*}{$\begin{array}{l}\text { Inadequate physical and } \\
\text { technical infrastructure }\end{array}$} & $\begin{array}{l}\text { - Services provided at different } \\
\text { locations }\end{array}$ \\
\hline & - Services not provided on same day \\
\hline \multirow[t]{2}{*}{$\begin{array}{l}\text { Ineffective procurement and } \\
\text { distribution systems }\end{array}$} & $\begin{array}{l}\text { - Patient drug procurement/ } \\
\text { administration at different locations }\end{array}$ \\
\hline & $\begin{array}{l}\text { - Inadequate and irregular supplies of } \\
\text { essential drugs and interventions }\end{array}$ \\
\hline $\begin{array}{l}\text { Inadequate information } \\
\text { systems }\end{array}$ & $\begin{array}{l}\text { - Weak monitoring and evaluation } \\
\text { systems }\end{array}$ \\
\hline \multirow[t]{2}{*}{ Insufficient human resources } & $\begin{array}{l}\text { - Staff shortages and overburdened } \\
\text { staff }\end{array}$ \\
\hline & - Frequently reallocated workforce \\
\hline
\end{tabular}

\section{Adoption system \\ Insufficient buy-in from healthcare implementers}

Inconsistent leadership and governance

\begin{tabular}{|c|c|}
\hline \multicolumn{2}{|c|}{$\bullet$ Poor adherence to guidelines } \\
\hline Broader context & \\
\hline \multirow[t]{4}{*}{$\begin{array}{l}\text { Patient-centred barriers to } \\
\text { service delivery }\end{array}$} & $\begin{array}{l}\text { - Attending multiple clinics on } \\
\text { separate occasions/locations }\end{array}$ \\
\hline & $\begin{array}{l}\text { - Time away from work/parenting } \\
\text { obligations }\end{array}$ \\
\hline & - Costly and timely transport options \\
\hline & - Lack of partner support \\
\hline \multirow[t]{2}{*}{ Cultural and social barriers } & $\begin{array}{l}\text { - Fear and stigma, lack of trust in } \\
\text { interventions }\end{array}$ \\
\hline & $\begin{array}{l}\text { - Societal attitudes towards HIV, } \\
\text { tuberculosis, malaria }\end{array}$ \\
\hline \multirow[t]{3}{*}{ Funding structures } & $\begin{array}{l}\text { - Historical focus on donor funding } \\
\text { to specific diseases }\end{array}$ \\
\hline & $\begin{array}{l}\text { - Siloed and disease-specific funding } \\
\text { models }\end{array}$ \\
\hline & $\begin{array}{l}\text { - Complexities of different levels of } \\
\text { government funding }\end{array}$ \\
\hline
\end{tabular}

Buy in can be affected by:

- Limited human resource capacity, time, training and financing for extra

- Service delivery tasks

- Lack of supervision

- Poor motivation

- Inconsistent national policies

- Inconsistent guidelines and training documents

- Poor adherence to guidelines

Attending multiple clinics on separate occasions/locations

Time away from work/parenting

government funding 
interventions into ANC services, implementation must be accompanied by improved physical and technical infrastructure; services provided at different locations (e.g. consulting rooms and laboratories in different facilities) or those not provided on the same day pose a significant challenge to integrated HIV services (reviewed in $[11,26,43])$ and have impacted on the integration of malaria treatment into ANC $[44,45]$. While IPTp is given presumptively in ANC, thus removing the need for testing, women are often required to purchase the drug elsewhere or are not directly observed taking therapy having been given the drug to take home, both of which have been identified as a significant barrier to IPTp coverage [45-47]. Effective procurement and distribution systems are also important determinants of success for integrated services, with inadequate and irregular supplies of essential drugs and interventions, in both the public and private healthcare sector, representing a major barrier in the uptake of both integrated HIV and malaria services [18, 39, 40].

The level of buy-in from staff and the capacity of service infrastructure to support the adoption of new service delivery models also represent key targets to overcome structural barriers for integrated ANC; here, adoptions systems influence the human resource characteristics of the health system (Table 3). Integrating service delivery of multiple interventions into ANC in resource-constrained settings such as sub-Saharan Africa can significantly impact the health workforce. Staff shortages, overburdened staff and a frequently re-allocated workforce have limited the success of HIV, TB and malaria service integration into ANC $[4,11,18,39,40$, 44, 47-55]. Together with unsupervised healthcare staff and a lack of adequately trained staff, these human resource constraints will affect motivation and buy-in from those charged with implementing integrated ANC. Furthermore, a lack of leadership and governance can compound the adoption of new health systems. For example, a study assessing the consistency of national-level policies and guidelines for malaria in pregnancy in five sub-Saharan Africa countries found major inconsistencies both within and between countries in national policy and training documents [56]. Poor adherence to guidelines [40], coupled with outdated and inconsistent guidelines, may lead to incorrect implementation of prevention and care strategies and low coverage of malaria, HIV and TB interventions into ANC.

By identifying common structural barriers to implementing integrated ANC in the health and adoption systems, enablers can also be identified to optimise service delivery and improve maternal and child health outcomes. Enablers that have helped overcome identified structural barriers in integrated ANC, reproductive health and primary care services include streamlined funding, effective distribution/logistical systems, integrated health information systems [21, 30, 33, 44], provision of all services on the same site [21, 57], free or low-cost testing and treatment [57], holistic, comprehensive healthcare delivered by multi-skilled health workers or different health workers under the same roof [57], provision of support (psychosocial, financial) to encourage treatment adherence and clinic attendance [57-59], and well-supported trained healthcare staff [33, 42, 49, 60-63]. Careful consideration of these enablers in the design and implementation of integrated ANC, HIV, TB and malaria services is required and will generate demand for such integrated services. It is also imperative to have appropriate process, outcome and impact evaluations that result in fundamental translatable outcomes for integrated ANC, HIV, TB and malaria services. Rigorous evaluations of the integration of multiple interventions into ANC are important given the integration of approaches to tackle multiple diseases may exponentially amplify implementation issues in the absence of appropriate infrastructure or human resource strengthening.

\section{Challenges in implementing integrated ANC in the broader context: patient- and community-centred barriers} In the broader context, the acceptability of models of health service delivery from a community and individual patient perspective can significantly impact the reach of health services and their effectiveness in achieving improved health outcomes (Table 3). Integrated ANC has the potential to either reduce or exacerbate (particularly for stigmatised diseases), patient-level barriers to care. Studies conducted in sub-Saharan Africa focusing on the integration of HIV testing and treatments into ANC clinics and IPTp access at ANC have cited the need to attend health clinics on multiple occasions and at separate locations, taking time away from work or parenting obligations, and costly and timely transport options as major barriers to returning to health clinics $[11,21,30$, 33, 64-68]. These access issues were relevant to receiving HIV test results and initiating and adhering to HIV treatment and PMTCT services [21, 29, 30, 33, 62, 64], and similar problems were identified with TB services and the need to return to clinics to provide a second sputum to confirm a diagnosis [65]. These considerations support the principles underpinning integrated ANC models by underscoring the importance of streamlining service provision across multiple antenatal and disease-specific needs.

While the convenience of an integrated approach appears favourable to the patient, the broader contexts in which different diseases are perceived within communities, including their social acceptability and potential diseaserelated stigmas, give rise to challenges for integrated ANC. In the case of malaria, a systematic review found that the general lack of awareness among women of why they were 
being given IPTp, as well as its safety, regimen or benefit, was a key barrier to the implementation of IPTp into ANC services [40,69]. Illness, shyness, low social position and lack of partner support were also identified as social barriers that prevented or delayed ANC attendance and IPTp adherence [40, 70-72]. Studies investigating social barriers to accessing HIV care in rural Kenya found that $82 \%$ of HIV-infected women preferred integrated HIV ANC services, with service satisfaction among HIVnegative women relatively unaffected by the provision of HIV care [64]. It was suggested that high levels of satisfaction among HIV negative women was potentially due to the limited distinction in observed care provided to women on the basis of their HIV status [64]. However, the potential remains for integrated HIV services to act as a barrier to ANC attendance. Data collected from a District Hospital in Western Kenya showed that pregnant women were anxious they would be tested for HIV without consent if they attended ANC clinics, with such concerns potentially hampering efforts to provide other health interventions through ANC clinics such as IPTp or insecticide-treated nets for malaria prevention [73]. Other studies identified the stigma and co-occurrence of HIV with $\mathrm{TB}$ as a potential barrier to integrated ANC service provision. Data collected from ANC clients and service providers in Malawi found stigma attached to TB was attributed to both fear of spread of infection and its association with HIV [65, 74]. Patients reported that 'new' TB was often perceived as being linked with HIV and expressed concern that TB patients were being viewed as AIDS patients [65]. Cultural and social barriers to healthcare, such as those associated with stigma, fear of diagnosis and a lack of trust, highlight the need for operational and implementation research to explore optimal ways to reduce these barriers.

\section{Concluding remarks in the broader context of funding structures}

Despite the long-standing endorsement of integrated ANC services to improve health outcomes among women and children at risk of HIV, TB and malaria, there is little literature to guide the implementation, refinement and evaluation of such services. There may be additional grey literature that describes successful service integration and it is imperative to develop avenues to consolidate this literature and make it accessible to researchers, program implementers and policymakers. The highest burden of these diseases is in sub-Saharan Africa, and what little published research exists on integrated ANC is focused there. However, the considerable variation in healthcare and the economic, social and political context in subSaharan Africa warrants further research on integrated ANC models representing a greater breadth of African countries. Studies outside of the African continent are also crucial to inform local models given the distinctive regional considerations, including those related to health systems, geography, the relative involvement of government, aid agencies and civil society in the provision of health services, and the social, cultural and legislative positions on specific diseases and their routes of transmission.

With the current transition to the SDGs and concerns centred around progress towards MDGs related to maternal, newborn and child health [9], the global health community, researchers, implementers and funding bodies must work together to ensure the establishment of quality operational and implementation research into models of integrated ANC that address multiple health outcomes. This is particularly pertinent because, while our essay concentrated on HIV, TB and malaria, other communicable and vaccine-preventable diseases (e.g. viral hepatitis) also feature in the new SDGs (end epidemics by 2030, Table 1) [2] alongside integration of reproductive health into national strategies [2], and have the potential to be incorporated into a program of integrated ANC. Recent analysis of disbursements of development assistance for health show that, following a decade of increased funds for the MDG-related diseases of HIV, TB and malaria, since 2010, funding for these diseases has largely flat-lined while funds for maternal, child and newborn health have increased [17]. The broader context of these changes in decisionmaking about global health funding priorities (Table 3) underscore a move away from single-disease funding allocations and an opportunity for significant progress towards improved maternal health outcomes through the SDGs. However, given the significant burden of disease that HIV, TB and malaria represent for young women and their children, integrated ANC is an increasingly important model to maintain progress on disease-specific prevention while simultaneously addressing shortfalls in maternal and child health outcomes. To achieve a successful transition to the SDGs and guide best practice approaches when international donor funding is static or predicted to decline, monitoring and evaluation systems need to accompany program implementation to determine the effectiveness of integrated models of ANC in improving health outcomes (Box 1). Increasing and sustaining investment in ANC is a predictable barrier to implementing and maintaining integrated ANC. It is therefore imperative, in the current economic climate, that practical and resource-efficient solutions to improving population-level health outcomes are found. With maternal, newborn and child morbidity and mortality remaining unacceptably high in resourceconstrained countries, especially in sub-Saharan Africa, the need for expanded operational research aiming to identify smarter solutions to improving maternal health is critical and requires strong leadership from the global health community. 


\section{Box 1: Recommendations for action}

At the macro-level:

- Global funding bodies ensure their monitoring and evaluation outcomes are aligned with the implementation and operational research outcomes of program implementers and researchers

- Global funding bodies make sufficient funding available to enable this data collection and analysis to occur as part of routine monitoring and evaluation

- Research institutes and global funding bodies work towards expanding global mentoring programs that provide training, guidance and support to implementers and researchers in low- and middle-income countries

- Program implementers and researchers work collaboratively to produce outcome-based research that results in academic publications as a form of dissemination of findings and in changes to policy and service delivery programs

At the implementation level:

- Streamlined funding, distribution/logistical systems, monitoring and evaluation systems

- Prioritise holistic, comprehensive healthcare

- Ensuring adequate resources and staff training, promote the development of a fluid multi-skilled workforce

- Increase physical and technical infrastructure and streamlining the provision of services to reduce attendance time and loss to follow-up

- Promote processes to facilitate same day provision of multiple clinical and preventive services

- Integration of consulting rooms with laboratory services

- Investment into point-of-care tests to alleviate the need for laboratories

- Provision of testing and treatment for free or at a low cost

- Provision of psychosocial support in encouraging treatment adherence and clinic attendance

- Ensuring similar levels of perceived antenatal care in diseaseaffected and unaffected women

- Increasing trust and consumer confidence in therapeutic efficacy of drugs and transparency around HIV testing

- Public education and health promotion strategies to increase disease awareness and trust in antenatal care intervention strategies

Research priorities:

- Determine the effectiveness of integrating tuberculosis care into antenatal clinics

- Monitor the therapeutic efficacy of treatment and prophylaxis in an era of emerging drug resistance
- Quantify the impact of enablers to reduce structural and patient-centred barriers on the uptake of HIV, tuberculosis and malaria services

- Quantify the impact of stand-alone versus cross-disease models of care

\section{Abbreviations}

AIDS: Acquired immunodeficiency syndrome; ANC: Antenatal care; HIV: Human immunodeficiency virus; IPTp: Intermittent preventive therapy of malaria in pregnancy; MDGs: Millennium development goals; PMTCT: Prevention of mother-to-child transmission; SDGs: Sustainable development goals; TB: Tuberculosis; WHO: World Health Organization

\section{Acknowledgements}

We thank Stanley Luchters for helpful comments on the manuscript.

\section{Funding}

This work was supported by the Australian Research Council (Future Fellowship to FJIF), National Health and Medical Research Council of Australia (Career Development Award to MS; Principal Research Fellowship to $\mathrm{MH}$ ), Infrastructure for Research Institutes Support Scheme Grant), and Victorian State Government Operational Infrastructure Support grant. The funding bodies had no role in data analysis, decision to publish, or preparation of the manuscript.

\section{Authors' contributions}

All authors wrote, read and approved the final manuscript.

\section{Competing interests}

The authors declare that they have no competing interests.

\section{Author details}

${ }^{1}$ Macfarlane Burnet Institute of Medical Research, Melbourne, Australia. 2Department of Epidemiology and Preventive Medicine, Monash University, Melbourne, Australia. ${ }^{3}$ Department of Infectious Diseases, Monash University, Melbourne, Australia. ${ }^{4}$ Centre for Epidemiology and Biostatistics, University of Melbourne, Melbourne, Australia.

Received: 28 June 2016 Accepted: 21 November 2016

Published online: 12 December 2016

\section{References}

1. United Nations. The millennium development goals report 2015. New York: UN; 2015.

2. United Nations. Sustainable development goals. NewYork: UN; 2015.

3. Silver KL, Singer PA. SDGs: start with maternal, newborn, and child health cluster. Lancet. 2014;384(9948):1093-4.

4. Lincetto O, Mothebesoane-Anoh S, Gomez P, Munjanja S. Chapter 2: antenatal care. In: Lawn J, Kerber K, editors. Opportunities for Africa's newborns: practical data, policy and programmatic support for newborn care in Africa. Geneva: WHO; 2006.

5. Mclntyre J. Mothers infected with HIV. Br Med Bull. 2003;67:127-35.

6. World Health Organization. Tuberculosis in women. Geneva: WHO; 2013.

7. The Interagency Task Team (IATT) on Prevention of HIV Infection in Pregnant Women MatC. Guidance on global scale-up of the prevention of mother-tochild transmission of HIV: towards universal access for women, infants and young children and eliminating HIV and AIDS among children. 2007.

8. World Health Organization. Malaria and HIV interactions and their implications for public health policy. Geneva: WHO; 2005.

9. Nations U. The millennium development goals report 2014. New York: United Nations; 2014.

10. Calvert C, Ronsmans C. The contribution of HIV to pregnancy-related mortality: a systematic review and meta-analysis. AIDS. 2013;27(10):1631-9.

11. Suthar AB, Hoos D, Beqiri A, Lorenz-Dehne K, McClure C, Duncombe C. Integrating anitretroviral therapy into antenatal care and maternal and child health settings: a systematic review and meta-analysis. Bull World Health Organ. 2013;91:46-56.

12. Darmstadt GL, Bhutta ZA, Cousens S, Adam T, Walker N, de Bernis L Lancet neonatal survival steering team. Evidence-based, cost-effective 
interventions: how many newborn babies can we save? Lancet. 2005; 365(9463):977-88.

13. Sugarman J, Colvin C, Moran AC, Oxlade O. Tuberculosis in pregnancy: an estimate of the global burden of disease. Lancet Glob Health. 2014;2(12):e710-6.

14. Mathad JS, Gupta A. Tuberculosis in pregnant and postpartum women: epidemiology, management, and research gaps. Clin Infect Dis. 2012;55(11): 1532-49.

15. Adhikari M. Tuberculosis and tuberculosis/HIV co-infection in pregnancy. Semin Fetal Neonatal Med. 2009;14(4):234-40.

16. Waddington C, Egger D. Technical brief No.1, 2008. Integrated health services - What and Why? Geneva: WHO; 2008.

17. Dieleman JL, Schneider MT, Haakenstad A, Singh L, Sadat N, Birger M, Reynolds A, Templin T, Hamavid H, Chapin A, et al. Development assistance for health: past trends, associations, and the future of international financial flows for health. Lancet. 2016;387(10037):2536-44.

18. de Jongh TE, Gurol-Urganci I, Allen E, Jiayue Zhu N, Atun R. Barriers and enablers to integrating maternal and child health services to antenatal care in low and middle income countries. BJOG. 2016;123(4):549-57.

19. Villar J, Bergsjo P. WHO antenatal care randomized trial: manual for the implementation of the new model. Geneva: WHO; 2002.

20. Villar J, Ba'aqeel H, Piaggio G, Lumbiganon P, Miguel Belizan J, Farnot U, Al-Mazrou Y, Carroli G, Pinol A, Donner A, et al. WHO antenatal care randomised trial for the evaluation of a new model of routine antenatal care. Lancet. 2001;357(9268):1551-64.

21. Killam W, Tambatamba B, Chintu N, Rouse D, Stringer E, Bweupe M, Yu Y, Stringer J. Antiretroviral therapy in antenatal care to increase treatment initiation in HIV-infected pregnant women: a stepped-wedge evaluation. AIDS. 2010;24(1):85-91.

22. Washington S, Owuor K, Turan JM, Steinfeld RL, Onono M, Shade SB, Bukusi EA, Ackers ML, Cohen CR. Implementation and operational research: effect of integration of HIV care and treatment into antenatal care clinics on mother-tochild HIV transmission and maternal outcomes in Nyanza, Kenya: results from the SHAIP cluster randomized controlled trial. J Acquir Immune Defic Syndr. 2015;69(5):e164-71.

23. Turan JM, Onono M, Steinfeld RL, Shade SB, Owuor K, Washington S, Bukusi EA, Ackers ML, Kioko J, Interis EC, et al. Implementation and operational research: effects of antenatal care and HIV treatment integration on elements of the PMTCT cascade: results from the SHAIP cluster-randomized controlled trial in Kenya. J Acquir Immune Defic Syndr. 2015;69(5):e172-81.

24. Herlihy JM, Hamomba L, Bonawitz R, Goggin CE, Sambambi K, Mwale J, Musonda V, Musokatwane K, Hopkins KL, Semrau K, et al. Implementation and operational research: integration of PMTCT and antenatal services improves combination antiretroviral therapy uptake for HIV-positive pregnant women in southern Zambia: a prototype for option B + ? J Acquir Immune Defic Syndr. 2015;70(4):e123-9.

25. An SJ, George AS, LeFevre A, Mpembeni R, Mosha I, Mohan D, Yang A, Chebet J, Lipingu C, Killewo J, et al. Program synergies and social relations: implications of integrating HIV testing and counselling into maternal health care on care seeking. BMC Public Health. 2015;15:24.

26. Stinson $K$, Jennings $K$, Myer L. Integration of antiretroviral therapy services into antenatal care increases treatment initiation during pregnancy: a cohort study. PLoS One. 2013;8(5):e63328.

27. Tudor Car L, Van Velthoven MH, Brusamento S, Elmoniry H, Car J, Majeed A, Tugwell P, Welch V, Marusic A, Atun R. Integrating prevention of mother-tochild HIV transmission programs to improve uptake: a systematic review. PLoS One. 2012;7(4):e35268.

28. Christie C, Steel-Duncan J, Palmer P, Pierre R, Harvey K, Johnson N, Samuels L, Dunkley-Thompson J, Singh-Minott I, Anderson M, et al. Paediatric and perinatal HIV/AIDS in Jamaica: an international leadership initiative, 2002-2007. West Indian Med J. 2008:57(3):204-15.

29. Tsague L, Tsiouris FO, Carter RJ, Mugisha V, Tene G, Nyankesha E, KoblaviDeme S, Mugwaneza P, Kayirangwa E, Sahabo R, et al. Comparing two service delivery models for the prevention of mother-to-child transmission (PMTCT) of HIV during transition from single-dose nevirapine to multi-drug antiretroviral regimens. BMC Public Health. 2010;10:753.

30. van den Akker T, Bemelmans M, Ford N, Jemu M, Diggle E, Scheffer S, Zulu I, Akesson A, Shea J. HIV care need not hamper maternity care: a descriptive analysis of integration of services in rural Malawi. BJOG. 2012;119(4):431-8.

31. van't Hoog A, Mbori-Ngacha D, Marum L, Otieno J, Misore A, Nganga L, DeCock K. Preventing mother-to-child transmission of HIV in western Kenya: operational issues. J Acquir Immune Defic Syndr. 2005;40:344-9.
32. Kasenga F, Byass $P$, Emmelin M, Hurtig A-K. The implications of policy changes on the uptake of a PMTCT programme in rural Malawi: first three years of experience. Glob Health Action. 2009;2. doi: 10.3402/gha.v2i0.1883.

33. Pfeiffer J, Montoya P, Baptista AJ, Karagianis M, Pugas MM, Micek M, Johnson W, Sherr K, Gimbel S, Baird S, et al. Integration of HIV/AIDS services into African primary health care: lessons learned for health system strengthening in Mozambique - a case study. J Int AIDS Soc. 2010;13:3.

34. World Health Organization. HIV/AIDS Factsheet. http://www.who.int/ mediacentre/factsheets/fs360/en/.

35. Joint United Nations Programme on HIV/AIDS (UNAIDS). 90-90-90: an ambitious treatment target to help end the AIDS epidemic. Geneva: UNAIDS; 2014.

36. Chemaitelly H, Awad SF, Shelton JD, Abu-Raddad $\sqcup$. Sources of HIV incidence among stable couples in sub-Saharan Africa. J Int AIDS Soc. 2014;17:18765.

37. World Health Organization. World malaria report 2015. Geneva: WHO; 2015.

38. Kenyan Ministry of Health. Integrating tuberculosis prevention and treatment into focused antenatal care in Eastern Province, Kenya: a pilot project. Nairobi: MoH; 2008.

39. Thiam S, Kimotho V, Gatonga P. Why are IPTp coverage targets so elusive in sub-Saharan Africa? a systematic review of health system barriers. Malar J. 2013;12:353

40. Hill J, D'Mello-Guyett L, Hoyt J, van Eijk AM, ter Kuile FO, Webster J. Women's access and provider practices for the case management of malaria during pregnancy: a systematic review and meta-analysis. PLoS Med. 2014;11(8):e1001688.

41. Ooms G, Van Damme W, Baker BK, Zeitz P, Schrecker T. The 'diagonal' approach to global fund financing: a cure for the broader malaise of health systems? Global Health. 2008;4:6.

42. Maternal Health Taskforce. Malaria in Pregnancy: Bring Maternal Health and Malaria Communities Together. Meeting Report. MiP Technical Meeting. Istanbul; 2012. https://www.mhtf.org/topics/malaria-in-pregnancy/malaria-inpregnancy-technical-meeting/.

43. Dinh TH, Kamb ML, Msimang V, Likibi M, Molebatsi T, Goldman T, Lewis DA. Integration of preventing mother-to-child transmission of HIV and syphilis testing and treatment in antenatal care services in the Northern Cape and Gauteng provinces, South Africa. Sex Transm Dis. 2013;40(11):846-51.

44. Uwimana J, Jackson D. Integration of tuberculosis and prevention of mother-to-child transmission of HIV programmes in South Africa. Int J Tuberc Lung Dis. 2013:17(10):1285-90.

45. Hill J, Kayentao K, Achieng F, Diarra S, Dellicour S, Diawara SI, Hamel MJ, Ouma P, Desai M, Doumbo OK, et al. Access and use of interventions to prevent and treat malaria among pregnant women in Kenya and Mali: a qualitative study. PLoS One. 2015;10(3):e0119848.

46. Arulogun $\mathrm{O}$, Okereke $\mathrm{C}$. Knowledge and practices of intermittent preventive treatment of malaria in pregnancy amoung health workders in a southwest local governement area of Nigeria. J Med Med Sci. 2012;3:415-22.

47. Onoka CA, Onwujekwe OE, Hanson K, Uzochukwu BS. Sub-optimal delivery of intermittent preventive treatment for malaria in pregnancy in Nigeria: influence of provider factors. Malar J. 2012;11:317.

48. Balira R, Mabey D, Weiss H, Ross DA, Changalucha J, Watson-Jones D. The need for further integration of services to prevent mother-to-child transmission of HIV and syphilis in Mwanza City, Tanzania. Int J Gynaecol Obstet. 2015;130 Suppl 1:S51-7.

49. Ahumuza SE, Rujumba J, Nkoyooyo A, Byaruhanga R, Wanyenze RK. Challenges encountered in providing integrated HIV, antenatal and postnatal care services: a case study of Katakwi and Mubende districts in Uganda. Reprod Health. 2016;13:41.

50. Crawley J, Hill J, Yartey J, Robalo M, Serufilira A, Ba-Nguz A, Roman E, Palmer A, Asamoa K, Steketee R. From evidence to action? challenges to policy change and programme delivery for malaria in pregnancy. Lancet Infect Dis. 2007;7(2):145-55.

51. Mubyazi G, Bloch P, Kamugisha M, Kitua A, ljumba J. Intermittent preventive treatment of malaria during pregnancy: a qualitative study of knowledge, attitudes and practices of district health managers, antenatal care staff and pregnant women in Korogwe District, North-Eastern Tanzania. Malaria J. 2005:4:31.

52. Mubyazi GM, Bloch P. Psychosocial, behavioural and health system barriers to delivery and uptake of intermittent preventive treatment of malaria in pregnancy in Tanzania - viewpoints of service providers in Mkuranga and Mufindi districts. BMC Health Serv Res. 2014;14:15.

53. Rassi C, Graham K, Mufubenga P, King R, Meier J, Gudoi SS. Assessing supply-side barriers to uptake of intermittent preventive treatment for 
malaria in pregnancy: a qualitative study and document and record review in two regions of Uganda. Malar J. 2016;15:341.

54. Yoder PS, Nsabagasani X, Eckert E, Moran A, Ye Y. Perspectives of health care providers on the provision of intermittent preventive treatment in pregnancy in health facilities in Malawi. BMC Health Serv Res. 2015;15:354.

55. Webster J, Kayentao K, Diarra S, Diawara SI, Haiballa AA, Doumbo OK, Hill J. A qualitative health systems effectiveness analysis of the prevention of malaria in pregnancy with intermittent preventive treatment and insecticide treated nets in Mali. PLoS One. 2013;8(7):e65437.

56. Gomez PP, Gutman J, Roman E, Dickerson A, Andre ZH, Youll S, Eckert E, Hamel MJ. Assessment of the consistency of national-level policies and guidelines for malaria in pregnancy in five African countries. Malar J. 2014; 13:212.

57. WHO, UNFPA, UNAIDS, IPPF. Linking sexual and reproductive health and HIV/ AIDS, gateways to integration: a case study from Haiti. Geneva: WHO; 2008

58. Peck R, Fitzgerald D, Liautaud B, Deschamps MM, Verdier Rl, Beaulieu ME, GrandPierre R, Joseph P, Severe P, Noel F, et al. The feasibility, demand, and effect of integrating primary care services with HIV voluntary counseling and testing: evaluation of a 15-year experience in Haiti, 1985-2000. J Acquir Immune Defic Syndr. 2003;33:470-5.

59. Koenig S, Ivers IC, Pace S, Destine R, Leandre F, GrandPierre R, Mukherjee J, Farmer PE, Pape JW. Successes and challenges of HIV treatment programs in Haiti: aftermath of the earthquake. HIV Ther. 2010;4(2):145-60.

60. van der Merwe K, Chersich MF, Technau K, Umurungi Y, Conradie F, Coovadia A. Integration of antiretroviral treatment within antenatal care in Gauteng Province, South Africa. J Acquir Immune Defic Syndr. 2006;43(5): 577-81.

61. Ginsburg AS, Hoblitzelle CW, Sripipatana TL, Wilfert CM. Provision of care following prevention of mother-to-child HIV transmission services in resource-limited settings. AIDS. 2007;21(18):2529-32.

62. Winestone LE, Bukusi EA, Cohen CR, Kwaro D, Schmidt NC, Turan JM. Acceptability and feasibility of integration of HIV care services into antenatal clinics in rural Kenya: a qualitative provider interview study. Glob Public Health. 2012;7(2):149-63.

63. Ouma PO, Van Eijk AM, Hamel MJ, Sikuku E, Odhiambo F, Munguti K, Ayisi $J G$, Kager PA, Slutsker L. The effect of health care worker training on the use of intermittent preventive treatment for malaria in pregnancy in rural western Kenya. Trop Med Int Health. 2007;12(8):953-61.

64. Vo B, Cohen C, Smith R, Bukusi E, Onono M, Doolan K, Washington S, Turan J. Patient satisfaction with integrated HIV and antenatal care services in rural Kenya. AIDS Care. 2012;24(11):1442-7.

65. Sangala WT, Briggs P, Theobald S, Squire SB, Kemp J. Screening for pulmonary tuberculosis: an acceptable intervention for antenatal care clients and providers? Int J Tuberc Lung Dis. 2006;10(7):789-94.

66. Mubyazi GM, Bygbjerg IC, Magnussen P, Olsen O, Byskov J, Hansen KS, Bloch P. Prospects, achievements, challenges and opportunities for scalingup malaria chemoprevention in pregnancy in Tanzania: the perspective of national level officers. Malar J. 2008;7:135.

67. Mbonye AK, Neema S, Magnussen P. Perceptions on use of sulfadoxinepyrimethamine in pregnancy and the policy implications for malaria control in Uganda. Health Policy. 2006;77(3):279-89.

68. Mubyazi GM, Bloch P, Magnussen P, Olsen OE, Byskov J, Hansen KS, Bygbjerg IC. Women's experiences and views about costs of seeking malaria chemoprevention and other antenatal services: a qualitative study from two districts in rural Tanzania. Malar J. 2010;9:54.

69. Rumisha SF, Zinga MM, Fahey CA, Wei D, Bwana VM, Mlozi MR, Shayo EH, Malima RC, Mayala BK, Stanley G, et al. Accessibility, availability and utilisation of malaria interventions among women of reproductive age in Kilosa district in central Tanzania. BMC Health Serv Res. 2014;14:452.

70. Sambili B, Kimambo R, Peng Y, Ishunga E, Matasha E, Matumu G, Noronha R, Ngilangwa DP. Factors influencing anti-malarial prophylaxis and iron supplementation non-compliance among pregnant women in Simiyu Region, Tanzania. Int J Environ Res Public Health. 2016;13(7). https://www. ncbi.nlm.nih.gov/pmc/articles/PMC4962167/.

71. Ameh S, Owoaje E, Oyo-Ita A, Kabiru CW, Akpet OE, Etokidem A, Enembe O, Ekpenyong N. Barriers to and determinants of the use of intermittent preventive treatment of malaria in pregnancy in Cross River State, Nigeria: a cross-sectional study. BMC Pregnancy Childbirth. 2016;16:99.

72. Mbonye AK, Yanow S, Birungi J, Magnussen P. A new strategy and its effect on adherence to intermittent preventive treatment of malaria in pregnancy in Uganda. BMC Pregnancy Childbirth. 2013;13:178.
73. Sande JH, Kaseje D, Nyapada L, Owino VO. Fear of being tested for HIV at ANC clinics associated with low uptake of intermittent preventive treatment (IPT) of malaria among pregnant women attending Bondo District Hospital, Western Kenya. East Afr J Public Health. 2010;7(1):92-6.

74. Kali P, Gray G, Violari A, Chaisson R, Mclntyre J, Martinson N. Combining PMTCT with active case finding for tuberculosis. J Acquir Immune Def Syndr. 2006:42:379-81.

75. UNICEF Data: Monitoring the Situation of Children and Women. http://data. unicef.org/. Accessed 20 Oct 2016.

76. Global Health Observatory (GHO) Data. http://www.who.int/gho/en/. Accessed 20 Oct 2016.

77. World Health Organization. Universal health coverage - at the centre of the health goal. In: World health statistics 2016: monitoring health for the SDGs. Geneva: WHO; 2016. p. 15-21.

78. World Health Organization. Antiretrovieral drugs for treating pregnant women and preventing HIV infection in infants: recommendations for a public health approach. Geneva: WHO; 2010.

79. World Health Organization. Programmatic update: use of antiretroviral drugs for treating pregnant women and preventing HIV infections in infants. Geneva: WHO; 2012.

80. World Health Organization. Consolidated ARV guidelines, June 2013: summary of new recommendations. Geneva: WHO; 2013.

81. World Health Organization. Guidelines for the treatment of malaria. 2nd ed. Geneva: WHO; 2010

82. World Health Organization. WHO policy brief for the implementation of intermittent preventive therapy of malaria in pregnancy using sulfadoxinepyrimethamine (IPTp-SP). Geneva: WHO; 2013.

83. World Health Organization. Treatment of tuberculosis: guidelines. 4th ed. Geneva: WHO; 2010

84. World Health Organization. WHO policy on collaborative TB/HIV activities: guidelines for National Programmes and other stakeholders. Geneva: WHO; 2012.

85. World Health Organization. Protecting all pregnant women and children under five years living in malaria endemic areas in Africa with insecticide treated mosquito nets. Geneva: WHO; 2006.

\section{Submit your next manuscript to BioMed Central and we will help you at every step:}

- We accept pre-submission inquiries

- Our selector tool helps you to find the most relevant journal

- We provide round the clock customer support

- Convenient online submission

- Thorough peer review

- Inclusion in PubMed and all major indexing services

- Maximum visibility for your research

Submit your manuscript at www.biomedcentral.com/submit
Biomed Central 